\title{
Changes in the Job Satisfaction of Village Clinic Doctors Since the New Health Care System Reform: A Comparison Based on Three Surveys in Shandong, China
}

\section{Zhongming Chen}

Weifang Medical University - Fuyanshan Campus: Weifang Medical University https://orcid.org/00000002-9378-6676

\section{Lifang Zhou}

Weifang Medical University - Fuyanshan Campus: Weifang Medical University Haiyuan Lv

Weifang Medical University - Fuyanshan Campus: Weifang Medical University Kui Sun

Weifang Medical University - Fuyanshan Campus: Weifang Medical University Hongwei Guo

Weifang Medical University - Fuyanshan Campus: Weifang Medical University Jinwei Hu

Weifang Medical University - Fuyanshan Campus: Weifang Medical University

Qianqian Yu

Weifang Medical University - Fuyanshan Campus: Weifang Medical University

\section{Dongmei Huang}

Weifang Medical University - Fuyanshan Campus: Weifang Medical University

\section{Dongping Ma}

Weifang Medical University - Fuyanshan Campus: Weifang Medical University

\section{Zhiqiang Feng}

Weifang Medical University - Fuyanshan Campus: Weifang Medical University

Changhai Tang

Weifang Medical University - Fuyanshan Campus: Weifang Medical University

\section{Mengna Dai}

Weifang Medical University - Fuyanshan Campus: Weifang Medical University Wenqiang Yin ( $\triangle$ yinwq1969@126.com )

Weifang Medical University - Fuyanshan Campus: Weifang Medical University https://orcid.org/00000001-7284-8359 


\section{Research Article}

Keywords: New health care system reform, village clinic doctors, job satisfaction.

Posted Date: May 4th, 2021

DOl: https://doi.org/10.21203/rs.3.rs-424447/v1

License: (c) (i) This work is licensed under a Creative Commons Attribution 4.0 International License. Read Full License 


\section{Abstract}

Background: In 2009, the Chinese government launched a new health care system reform. One of the important aims of the reform was to improve the capacity of primary health institutions. Village clinic doctors are part of the health service force rooted in rural China and the basis of the three-tiered health service system. The job satisfaction of village clinic doctors has an important impact on the stability and sustainable development of the three-tiered health service system. This study aimed to analyse the changes in village clinic doctors' job satisfaction after the implementation of the new health care system reform.

\section{Methods:}

All the data came from three surveys of village clinic doctors in Shandong Province conducted in 2012, 2015 and 2018. In 2012, an originally designed questionnaire was used to conduct a baseline survey of 405 village clinic doctors from 27 townships in 9 counties (the response rate was 92.9\%). In 2015 and 2018,519 and 223 village clinic doctors in the same counties were surveyed with the same questionnaire (the response rates were $94.3 \%$ and $92.9 \%$, respectively). Descriptive analysis, $\chi 2$ test and ANOVA were used to analyse the level of and changes in village clinic doctors' job satisfaction.

Results: The mean scores of village clinic doctors' total job satisfaction were $2.664 \pm 1.069,3.121 \pm$ 0.931 and $2.676 \pm 1.044$ in 2012, 2015 and 2018, respectively, with a significant difference $(F=28.732, P$ $<0.001)$. The mean scores of the medical practice environment and the job itself showed a continuous downward trend. The change trends of the mean scores for job reward, internal work environment and organizational management were consistent with the trend for total job satisfaction.

Conclusion: After the implementation of the NHCSR, the job satisfaction of village clinic doctors showed a trend of first rising and then falling. To improve primary health care service capacity, the Chinese government has implemented a series of new reform policies. With their ongoing implementation, village clinic doctors' job satisfaction should be the subject of more systematic and detailed research.

\section{Background}

As an important indicator of human resource management, job satisfaction (JB) refers to the positive emotional state of employees regarding their work or work experience ${ }^{[1]}$. Previous studies ${ }^{[2]-[5]}$ showed that doctors' JS was an important factor affecting not only the stability of the doctors' jobs and the health system over all but also health service quality and patient satisfaction. Village clinic doctors (VCDs) are health workers rooted in rural China, originating from the "barefoot doctors" in the early days of the founding of the People's Republic of China. They are the cornerstone of the three-tiered health service system. For a long time, VCDs played an important role in ensuring the health of rural residents, and they were known as the health protectors of rural residents ${ }^{[6]}$. According to the statistics of the National Health Commission of the People's Republic of China, since 2011, the annual number of visits to village clinics has amounted to more than 1.6 billion, accounting for more than $37 \%$ of the visits to 
primary medical institutions. A high level of JS among VCDs is conducive not only to supporting the stability and sustainable development of the health service system but also to providing better medical services for rural patients ${ }^{[7]-[8]}$.

Inadequate health resources and health service capacity at the primary level (especially in rural areas) have been problems in China's health system, directly leading to and aggravating the difficulty and expense of medical treatment. To effectively solve these problems, the Chinese government launched the new health care system reform (NHCSR)in 2009, which adheres to the basic principles of "ensuring the basics, strengthening the locals and constructing the mechanisms". During the first phase of the reform (2009-2011), the focus of the reform was on constructing a basic medical service system, basic public health service system, basic medical insurance and essential medicine system to strengthen the capacity of primary health services ${ }^{[9]}$. In 2015, the State Council put forward the implementation of the grading healthcare system ${ }^{[10]}$, aiming to improve the quality of primary health services and attract patients to primary health institutions to promote the formation of a reasonable order of diagnosis and treatment. In 2018, the Central Committee of the Communist Party of China put forward the "Rural Revitalization Strategy" $[11]$, which calls for "healthy rural" construction and proposes higher requirements for village-level health services. Undoubtedly, VCDs have been the focus of the NHCSR. However, statistics showed that [12] from 2009 to 2013, the annual number of visits to village clinics increased from 1.552 billion to 2.012 billion. However, by 2018 , the annual number of visits to village clinics had dropped to 1.67 billion, and the proportion of visits to clinics had dropped to $20.1 \%$ from $27.51 \%$ (2013-year).

Since the NHCSR was implemented, VCDs have received increasing attention among health management researchers. Previous studies ${ }^{[13]-[19]}$ covered aspects such as VCDs' service capacity, team building, education and training, income treatment, professional mentality, incentive and restraint mechanisms, recognition and evaluation of the NHCSR. Regarding VCDs' JS, Zhang Qi et al. studied the current level of the JS of VCDs in western China, and the results showed that $44.6 \%$ of VCDs expressed dissatisfaction with their work. ${ }^{20]}$ Zhang Xiaoyan et al. described the current situation of VCDs' JS in Jiangxi Province, and the results showed that $87.28 \%$ of VCDs expressed dissatisfaction. ${ }^{[21]}$ Ding Haiyun et al. described the current JS of VCDs in Nanjing, and the results showed that $46.5 \%$ of VCDs were dissatisfied with their job. ${ }^{[22]}$ Sun Qiaoqiao et al. described the income satisfaction of VCDs, and the results showed that $29.9 \%$ of VCDs were not satisfied with the current monthly average income level. ${ }^{[23]}$ Chen Ruixia et al. studied the training satisfaction of VCDs, and the results showed that $86.47 \%$ of VCDs were satisfied with the current professional training. ${ }^{[24]}$ Yang Miao analysed gender differences in the JS of VCDs in western China. The results showed that the JS of male VCDs was $3.16 \pm 0.74$ and that of female VCDs was 3.22 \pm 0.66. ${ }^{[25]}$

Most previous studies were cross-sectional studies conducted at a certain moment in time. Although most of the studies discuss the impact of the NHCSR on VCDs' JS, they cannot directly reflect the changes in the JS of VCDs since the implementation of the NHCSR. With the data of three surveys on VCDs conducted in Shandong Province in 2012, 2015 and 2018, this study analysed the changes in the 
JS of VCDs since the NHCSR and discussed the possible reasons for these changes from the perspective of the NHCSR. The results of this study provide a basis and reference for improving the JS and stability of VCDs.

\section{Methods}

\section{Methods}

\section{Sampling}

Shandong Province is a province in eastern China. In 2019, Shandong Province had 16 prefecture-level cities (an administrative level below the province and above the county; there were 17 prefecture-level cities in and before 2018), a population of 100.70 million (including a rural population of 38.76 million) and a per capita GDP of 70,653 yuan and belonged to the economically developed regions of China. In 2018, there were 53,246 village clinics and 96,253 VCDs in Shandong Province. On average, there were 1.8 VCDs in each village clinic. All the data in this study came from three surveys of VCDs held in Shandong Province in 2012, 2015 and 2018, with 405, 519 and 223 valid questionnaires and response rates of $92.9 \%, 94.3 \%$ and $92.9 \%$, respectively. In 2012 , we conducted a baseline survey using a multistage sampling method. First, according to the economic level, three prefecture-level cities, Jinan, Linyi and Dezhou, were selected from 17 prefecture-level cities in Shandong Province, which represent economically developed areas, moderately developed areas and underdeveloped areas, respectively. Then, three counties with different economic levels were randomly selected from each prefecture-level city, three townships were randomly selected from each county, and one village clinic doctor was randomly selected from each village clinic in the three townships to fill in the questionnaire in the township health centre. The participants were randomly selected using the envelope method. In 2015 and 2018, follow-up surveys were conducted, but thanks to urbanization and regional health development in recent years, some village clinics were abolished or merged and could not be traced. Coupled with the demission of VCDs, ${ }^{[26]-[27]}$ the number of VCDs decreased, resulting in a larger reduction in the sample size in 2018. To ensure that the privacy of the respondents' information was effectively protected, the survey was carried out anonymously by a self-administered questionnaire. All the respondents were fully informed of the value and significance of the survey to improve the response rate. All investigators were trained intensively before the investigation to ensure survey quality.

\section{Measurement instruments}

The Chinese Physicians' Job Satisfaction Questionnaire compiled by Yin WQ et al. was used to measure the JS of VCDs. ${ }^{[28]-[29]}$ It included satisfaction with the job itself (such as job significance, professional interest and job value), satisfaction with job rewards (such as income level, rationality of income distribution, opportunities for further study and promotion of professional titles), satisfaction with the internal working environment (such as office environment, equipment resources, colleague relationships), satisfaction with the medical practice environment (such as doctor-patient relationships, social 
recognition), and satisfaction with organizational management (such as management system, leadership behaviour, identification with the organization). All the items were rated with a five-point Likert scale, ranging from 1 (very dissatisfied) to 5 (very satisfied). The medical practice environment is a negative item, so it is reverse scored. This questionnaire has been used in many studies and has been verified to have good reliability and validity. ${ }^{[30]-[32]}$

\section{Statistical analysis}

First, descriptive analysis was conducted on the demographic characteristics and JS of VCDs. Then, $\chi^{2}$ test, one-way ANOVA and post hoc least-significant difference (LSD) were adopted to compare the differences in JS among groups. The significance level of all tests was set at $P<0.05$ (two-tailed).

\section{Results}

\section{Demographic Characteristics}

The demographic characteristics of the participants in the three surveys in 2012, 2015 and 2018 are shown in Table 1. Male VCDs accounted for $60.5 \%, 65.9 \%$ and $68.2 \%$ of the doctors surveyed in each year, respectively. Most of the village doctors were aged 31 to 40 years, accounting for $39.8 \%, 39.9 \%$ and $36.3 \%$ in each survey year, respectively. The proportion of village doctors aged $41-50$ showed an upward trend, from $27.3 \%$ in 2012 to $35.9 \%$ in 2018. In the three surveys, most VCDs were married, accounting for $96 \%, 95.9 \%$ and $98.2 \%$. In terms of education distribution, doctors with secondary school education accounted for $75.5 \%, 75.2 \%$ and $73.4 \%$, respectively. In terms of professional qualifications, the largest proportion of VCDs had the professional qualifications of village doctors (a qualification formulated by the Chinese health administrative departments for medical personnel working in village clinics, which requires lower competence than that of licensed assistant doctors and whose scope of practice is general medicine), accounting for $55.6 \%$ and $87.1 \%$, and $72.3 \%$. In the three surveys, more than $85 \%$ of the VCDs were located in village clinics that participated in the integrated management led by township health centres.

By $\chi^{2}$ test, differences in the gender composition, age composition, marital status, and education distribution of VCDs among the three surveys were not statistically significant. Differences in the qualifications and integration care participation of VCDs across the three surveys were statistically significant. The proportion of VCDs with medical practitioners and assistant medical practitioners showed first a declining and then an increasing trend from 2012 to 2018. The proportion of VCDs with medical practitioners was highest in 2012, with $30.7 \%$. The proportion of VCDs participating in integrated care showed an upward tendency. In the survey in 2018, almost all VCDs (97.8\%) participated in integrated care. 
Table 1

Demographic characteristics of VCDs in 3 surveys

\begin{tabular}{|c|c|c|c|c|c|}
\hline \multirow[t]{2}{*}{ Characteristics } & $\begin{array}{l}\text { 2012(N = } \\
405)\end{array}$ & $\begin{array}{l}2015(\mathrm{~N}= \\
519)\end{array}$ & $\begin{array}{l}2018(\mathrm{~N}= \\
223)\end{array}$ & \multirow[t]{2}{*}{$x^{2}$} & \multirow[t]{2}{*}{$P$} \\
\hline & $\mathbf{N}(\%)$ & $\mathbf{N}(\%)$ & $\mathbf{N}(\%)$ & & \\
\hline \multicolumn{6}{|l|}{ Gender } \\
\hline Male & $245(60.5)$ & $342(65.9)$ & $152(68.2)$ & \multirow[t]{2}{*}{4.579} & \multirow[t]{2}{*}{0.101} \\
\hline Female & $160(39.5)$ & $177(34.1)$ & $71(31.8)$ & & \\
\hline \multicolumn{6}{|l|}{ Age } \\
\hline$\leq 30$ & $33(8.3)$ & $28(5.4)$ & $9(4.0)$ & \multirow[t]{4}{*}{10.441} & \multirow[t]{4}{*}{0.107} \\
\hline $31 \sim$ & 159 (39.8) & 207 (39.9) & $81(36.3)$ & & \\
\hline $41 \sim$ & 109 (27.3) & $171(32.9)$ & $80(35.9)$ & & \\
\hline $51 \sim$ & $99(24.8)$ & $113(21.8)$ & $53(23.8)$ & & \\
\hline \multicolumn{6}{|l|}{ Marital status } \\
\hline Unmarried/widowed/divorced & $16(4.0)$ & $21(4.1)$ & $4(1.8)$ & \multirow[t]{2}{*}{3.537} & \multirow[t]{2}{*}{0.171} \\
\hline Married & $389(96.0)$ & $496(95.9)$ & $219(98.2)$ & & \\
\hline \multicolumn{6}{|l|}{ Educational background ${ }^{a}$} \\
\hline $\begin{array}{l}\text { No medical educational } \\
\text { background }\end{array}$ & $35(8.7)$ & $39(7.6)$ & $10(4.5)$ & \multirow[t]{3}{*}{6.797} & \multirow[t]{3}{*}{0.147} \\
\hline $\begin{array}{l}\text { Secondary technical school } \\
\text { graduates }\end{array}$ & $305(75.5)$ & $386(75.2)$ & $163(73.4)$ & & \\
\hline Junior college degree or higher & $64(15.8)$ & $88(17.2)$ & $49(22.1)$ & & \\
\hline \multicolumn{6}{|l|}{ Practice qualification ${ }^{a}$} \\
\hline Medical practitioner & $112(30.7)$ & $34(6.6)$ & $21(9.5)$ & \multirow[t]{3}{*}{139.627} & \multirow{3}{*}{$<0.001$} \\
\hline Assistant medical practitioner & $50(13.7)$ & $33(6.4)$ & $40(18.2)$ & & \\
\hline $\begin{array}{l}\text { Practice qualifications of rural } \\
\text { doctors }\end{array}$ & $203(55.6)$ & $452(87.1)$ & $159(72.3)$ & & \\
\hline \multicolumn{6}{|l|}{ Integrated care ${ }^{a}$} \\
\hline Yes & $344(87.8)$ & $495(96.1)$ & $218(97.8)$ & \multirow[t]{2}{*}{33.932} & \multirow{2}{*}{$<.001$} \\
\hline No & $48(12.2)$ & $20(3.9)$ & $5(2.2)$ & & \\
\hline
\end{tabular}

Percentage of VCDs with missing data on age (1.2\% in 2012), marital status (0.4\% in 2015), educational background (0.2\% in 2012, 1.2\% in 2015 and $0.4 \%$ in 2018), practice qualification (9.9\% in 2012 and $1.3 \%$ 
in 2018), and integrated care (3.2\% in 2012 and $0.7 \%$ in 2015).

\section{Job Satisfaction Comparison}

The results of VCDs' JS across the 3 surveys are shown in Table 2. First, we consider the change in the job itself satisfaction score. According to the results of one-way ANOVA, the mean score of VCDs' job itself satisfaction showed a downward trend $(F=113.696, P<0.001)$. According to the results of the LSD test, the scores for the satisfaction with the job itself in 2015 and 2012 were not significantly different, with values of $2.769 \pm 0.741$ and $2.819 \pm 0.837$, respectively. However, the score was significantly lower in $2018(1.921 \pm 0.715)$ than in 2012 and 2015 .

Second, the change in the job reward satisfaction score. According to the results of one-way ANOVA, the mean score of VCDs' job reward satisfaction first increased and then decreased $(F=26.569, P<0.001)$. According to the results of the LSD test, the scores for job reward satisfaction in 2012, 2015 and 2018 were significantly different, with $1.991 \pm 0.931,2.233 \pm 0.728$ and $1.769 \pm 0.852$, respectively.

Third, the change in the internal work environment satisfaction score. According to the results of one-way ANOVA, the mean score of VCDs' internal work environment satisfaction first increased and then decreased $(F=25.630, P<0.001)$. According to the results of the LSD test, the difference in internal work environment satisfaction between 2012 and 2015 was not statistically significant, with values of $3.071 \pm$ 0.722 and $3.117 \pm 0.604$, respectively. However, the score was significantly lower in $2018(2.735 \pm 0.762)$ than in 2012 and 2015.

Fourth, the change in the score for satisfaction with the medical practice environment. According to the results of the one-way ANOVA test, the mean score of VCDs' satisfaction with the medical practice environment showed a downward trend $(F=478.539, P<0.001)$. According to the results of the LSD test, the scores for satisfaction with the medical practice environment across 2012, 2015 and 2018 were significantly different, with $3.249 \pm 0.876,2.069 \pm 0.739$ and $1.385 \pm 0.626$, respectively.

Fifth, the change in the score for the satisfaction with organizational management. According to the results of the one-way ANOVA test, the mean score of VCDs' satisfaction with organizational management first increased and then decreased $(F=15.793, P<0.001)$. According to the results of the LSD test, the scores for the satisfaction with organizational management between 2012 and 2018 were not significantly different, with values of $2.854 \pm 0.906$ and $2.960 \pm 0.761$, respectively. However, the score was significantly higher in $2015(3.168 \pm 0.787)$ than in 2012 and 2018.

Finally, the change in the total JS score. The results showed that the mean score of VCDs' total JS first increased and then decreased $(F=28.732, P<0.001)$. According to the results of the LSD test, the scores for total JS in 2012 and 2018 were not significantly different, with values of $2.664 \pm 1.069$ and $2.676 \pm$ 1.044 , respectively. However, the score was significantly higher in $2015(3.121 \pm 0.931)$ than in 2012 and 2018. 
Table 2

Comparison of VCDs' JS in 3 surveys

\begin{tabular}{|llllll|}
\hline Items & $\mathbf{2 0 1 2}(\overline{\mathbf{x}} \pm$ & $\mathbf{2 0 1 5}(\overline{\mathbf{x}} \pm$ & $\mathbf{2 0 1 8}(\overline{\mathbf{x}} \pm$ & $\boldsymbol{F}$ & $P$ \\
& $\mathbf{S})$ & $\mathbf{S})$ & $\mathbf{S})$ & & \\
\hline Satisfaction with the job itself & $2.819 \pm$ & $2.769 \pm$ & $1.921 \pm$ & 113.696 & $<$ \\
& 0.837 & 0.741 & 0.715 & & 0.001 \\
\hline Job rewards satisfaction & $1.991 \pm$ & $2.233 \pm$ & $1.769 \pm$ & 26.569 & $<$ \\
& 0.931 & 0.728 & 0.852 & & 0.001 \\
\hline Internal work environment & $3.071 \pm$ & $3.117 \pm$ & $2.735 \pm$ & 25.630 & $<$ \\
satisfaction & 0.722 & 0.604 & 0.762 & & 0.001 \\
Medical practice environment & $3.249 \pm$ & $2.069 \pm$ & $1.385 \pm$ & 478.539 & $<$ \\
satisfaction & 0.876 & 0.739 & 0.626 & & 0.001 \\
Organizational management & $2.854 \pm$ & $3.168 \pm$ & $2.960 \pm$ & 15.793 & $<$ \\
satisfaction & 0.906 & 0.787 & 0.761 & & 0.001 \\
\hline Total JS & $2.664 \pm$ & $3.121 \pm$ & $2.676 \pm$ & 28.732 & $<$ \\
& 1.069 & 0.931 & 1.044 & & 0.001 \\
\hline
\end{tabular}

\section{Discussion}

With the implementation of a healthy rural strategy and a graded health care system, VCDs have been given new and higher requirements. Analysing the JS of VCDs not only is an urgent requirement to improve the capacity of primary health institutions and stabilize the three-tiered health service system but also plays an important role in implementing the principle of "strengthening the locals" in the NHCSR.

\section{The total JS of VCDs showed a downward trend after the first rise}

The results of the survey in 2012 showed that the mean scores of satisfactions with the medical practice environment and internal work environment were high, reaching $3.249 \pm 0.876$ and $3.071 \pm 0.722$, respectively. To a certain extent, this showed that the NHCSR had achieved remarkable results at the beginning. In 2009, China started the NHCSR based on the basic principles of "ensuring the basics, strengthening the locals, constructing the mechanisms", and 2009-2011 was the first stage of the reform. During this period, the Chinese government issued a series of policies aimed at strengthening the construction of primary health institutions and improving primary health facilities. ${ }^{[3]}$ Therefore, the mean score of satisfaction with the internal work environment was higher than the scores of other aspects (except medical practice environment). This was consistent with the finding of Li Jing et al. [34] The improvement in the buildings and health facilities of village clinics significantly improved the recognition of village clinics among rural residents. Moreover, a series of policies to support the development of primary health institutions was implemented. As a result, the mean score of satisfaction with the medical practice environment was higher than the scores of other aspects. This was also consistent with the finding of Xu Qionghua et al. ${ }^{[35]}$ The results of the survey in 2015 showed that the mean score of the total JS of VCDs was higher than that in 2012. This was mainly attributed to the 
improvement in VCDs' satisfaction with job rewards and organizational management. The results of the survey in 2018 showed that the mean score of the total JS of VCDs was lower than the score in 2015. The scores for four of the five dimensions of JS decreased. One possible reason was that VCDs' expectations for their work increased, such that the JS level decreased. This phenomenon is still worthy of the attention of health management researchers and policymakers.

\section{Satisfaction with job rewards, internal work environment and organizational management showed a downward trend after the first rise}

The year 2015 marked the close of the 12th Five-Year Plan for China's National Economic and Social Development (2011-2015). Over these years, government investment in primary health institutions, such as village clinics, continued to increase, leading to the optimization of the buildings and health facilities of village clinics and increasing the financial subsidies for VCDs. Moreover, the management system and security policies of primary health gradually improved. ${ }^{[36][37]}$ Therefore, the scores of the satisfaction with the three indicators improved compared with the results of the survey in 2012. However, there are many reasons for the decline in the scores for the three indicators in 2018. First, the increase in financial subsidies for VCDs has been slow. After the implementation of the NHCSR, subsidies for the essential medicine system and basic public health services became the main sources of income for VCDs. The subsidy of the essential medicine system is the "recurrent balance of revenue and expenditure subsidy" issued by the government for government-run village clinics that implemented the essential medicine system. The amount of compensation is related to the size of the population served by the VCDs, not the actual balance of income and expenditure of village clinics. Moreover, the level of compensation is low. [38]-[39] The subsidy of basic public health services is granted by the government to VCDs who provide basic public health services. It increased from 15 yuan per service population in 2011 (of which 40\% were allocated to VCDs) to 69 yuan in 2019. ${ }^{[40]-[41]}$ Beginning in 2014, this policy required that all the new compensation funds in rural areas be used in village clinics, which means that the current level is approximately 47 yuan per service population. The subsidy level is directly related to the population served by VCDs and affected by the hollowing of rural areas. In recent years, although the standard of financial subsidies has continuously improved, the actual financial subsidies of VCDs have not increased significantly. Second, the pressure brought by increased workload has been much higher than the sense of gain brought by the increased income for VCDs. For example, before the NHCSR, VCDs only undertook tasks related to basic medical services. However, after the implementation of the NHCSR, basic public health services were added, and the service content increased from 9 to 12 main functions. ${ }^{[0]-[41]}$ In addition, the increase in workload extended the part-time working hours of VCDs. Previous studies have shown that most VCDs work part-time in agricultural production, commercial activities or temporary employment, ${ }^{[20]}$ in addition to providing health services, to effectively provide for their families. However, with the increasing workload, VCDs have had to spend more time working to provide health services, resulting in the continuous reduction in income from their other part-time jobs. Third, there is no sustainable long-term investment mechanism for the construction of village clinics and health facilities;

${ }^{[42]}$ instead, the government has most often provided one-time investment in infrastructure construction, 
purchasing and maintenance of health facilities of village clinics. The health facilities that received investment in the initial stage of the NHCSR have gradually aged, which makes it difficult for doctors to meet the needs of rural patients. Therefore, the limitations of health facilities are another important factor restricting VCDs from providing medical services. Fourth, the operating funds of village clinics are not guaranteed. This leads to a poor medical environment in village clinics. ${ }^{[43]}$ Because all the subsidies are related to the service population, without connection to the actual burden of operating a given village clinic, VCDs have to minimize expenditure to control the operating costs of the clinic. This inevitably has a negative impact on the medical environment of the village clinics. A fifth problem regards the continuous adjustment of basic public health services. The project has played a vital role in promoting health. However, the continuous adjustment of technical specifications and assessment systems has caused confusion among VCDs. ${ }^{[44]}$ Sixth, the incentive mechanism is not perfect. On the one hand, the level of matching between incentive measures and the incentive preference of village doctors is low. Problems that concern VCDs, such as professional risks, welfare and personal income, have not been effectively solved. ${ }^{[45]}$ On the other hand, the connection between personal efforts and work performance is not strong enough. There is an egalitarian tendency in the granting of financial subsidies, which inhibits the enthusiasm of VCDs to some extent. ${ }^{[46]}$

\section{Satisfaction with the medical practice environment and the job itself showed a trend of continuous decline}

There are five possible reasons for the decline in satisfaction with these aspects. First, the frequent doctor-patient disputes in China in recent years have placed great psychological pressure on VCDs, which has been confirmed by the studies of Hesketh Therese, Wu Dan et al. ${ }^{[47][48]}$ Second, the protection mechanism for medical disputes of VCDs is imperfect. VCDs in most areas do not have medical dispute liability sharing insurance. Moreover, some VCDs who purchase medical dispute liability sharing insurance cannot be protected by the insurance because of a series of problems, such as high restrictions and little compensation. ${ }^{[49]}$ Third, doctors face competition from private clinics and the attraction of doctors from county-level medical institutions. ${ }^{[50]-[51]}$ Fourth, the career prospects of VCDs are not optimistic. On the one hand, the status of most VCDs is still "semi-agricultural and semi-medical". It is difficult for VCDs to obtain the same promotion opportunities regarding professional title as other medical staff. ${ }^{[52]}$ On the other hand, because they have experience mainly with single diseases and simple conditions, young and middle-aged VCDs' professional ability improvement is slow, so they have a low sense of achievement and personal value. Fifth, VCDs' work autonomy is insufficient. The main manifestation of this is the limitation of drug use. Since the implementation of the NHCSR, all government-run primary health institutions have had to implement the essential medicine system. This policy limits VCDs to prescribing only essential medicines. ${ }^{[53]}$ Moreover, with the advancement of the NHCSR, the implementation and supervision of this policy is becoming increasingly stringent. This regulation effectively controls the abuse of antibiotics and injections in rural areas ${ }^{[54]-[55]}$ but greatly restricts the autonomy of drug prescription by VCDs and weakens the medical service capacity of village clinics to some extent. ${ }^{[51]}$ As a result, VCDs find it increasingly difficult to meet the requirements of their 
jobs. The results of the survey in 2012 showed that the VCDs were most dissatisfied with job rewards, while according to the surveys of 2015 and 2018, they were most dissatisfied with the medical practice environment, and their satisfaction was lower in 2018 than in 2015. This indicated that the deteriorating medical practice environment had an increasingly serious impact on the JS of VCDs. This is basically consistent with the findings of Gan Yong et al. for general practitioners. [56]

This is the first study to monitor the JS of VCDs over time since the implementation of the NHCSR in China. Some limitations of the study should be noted. First, a self-report questionnaire was used to collect information. Social desirability effect caused by observation bias was therefore unavoidable. Second, because influencing factors were not investigated, the reasons for the changes in VCDs' JS may not be limited to those mentioned in this paper. Third, because the places where the VCDs practised were relatively scattered and there were only 1-2 doctors in most village clinics, it was difficult to carry out a large sample follow-up survey. Influenced by the sample size, the results of this study may offer limited representativeness regarding the JS of VCDs in China.

\section{Conclusion}

After the implementation of the NHCSR, the JS of VCDs showed a trend of first rising and then falling. Specifically, satisfaction with the medical practice environment and the job itself showed a continuous downward trend. The change trends of satisfaction with job reward, internal work environment and organizational management were consistent with the trend of total JS. At the beginning of the NHCSR, VCDs were mainly dissatisfied with job rewards, while in the middle and late stages of the NHCSR, the subject of their dissatisfaction shifted to the medical practice environment. In recent years, the Chinese government has launched a series of reform policies focusing on the construction of a regional medical consortium and the reform of a medical insurance payment system, together with the development and promotion of internet medical technology. All of these factors provide new impetus and hope for VCDs. Therefore, more systematic and detailed research should be carried out to accurately observe the impact of the NHCSR on the JS of VCDs.

\section{Abbreviations}

NHCSR: new health care system reform; ANOVA: Analysis of variance; LSD: least-significant difference; JB: job satisfaction; VCDs: village clinic doctors.

\section{Declarations}

\section{Acknowledgements}

We would like to thank the village clinic doctors who participated in this research.

\section{Funding}


This work was supported by the National Natural Science Foundation of China $(71804131,71804130$ and 71373182) and a project of Shandong Province Higher Educational Science and Technology Program (J18RA052).

\section{Availability of data and materials}

Data may be made available by the authors upon request.

\section{Authors' contributions}

This manuscript was jointly completed by ZC, LZ, HL, KS, HG, JH, QY, DH, DM, ZF, CT, MD and WY. ZC and WY obtained funding. ZC and WY designed the study. ZC, KS, HG, JH, QY, DH, DM, ZF, CT, and MD collected the data. ZC, LZ, HL, DM, ZF and CT were involved in data cleaning. ZC, LZ, HL, KS, and HG analysed the data. ZC and WY drafted the manuscript. $\mathrm{LZ}, \mathrm{HL}, \mathrm{JH}, \mathrm{QY}$ and $\mathrm{DH}$ contributed to the interpretation of the results and critical revision of the manuscript and approved the final version of the manuscript. All authors have read and approved the final manuscript.

\section{Ethical approval and consent to participate}

No ethical approval required for this study. All participants read a statement that explained the purpose of the survey. Written informed consent was obtained from all participants in this study.

\section{Competing interests}

The authors declare that they have no conflicts of interest.

\section{References}

1. Weiss HM. Deconstructing job satisfaction: Separating evaluations, beliefs and affective experiences[J]. Human Resource Management Review. 2002;12(2):173-94.

2. Zhou X, Pu J, Zhong X, et al. Burnout, psychological morbidity, job stress, and job satisfaction in Chinese neurologists[J]. Neurology. 2017;88:1727-35.

3. Aldrees T, Al-Eissa S, Badri M, et al. Physician job satisfaction in Saudi Arabia: insights from a tertiary hospital survey. Ann Saudi Med. 2015;35(3):210-3.

4. Lu Y, Hu X, Huang $X$, et al. Job satisfaction and associated factors among healthcare staff: a crosssectional study in Guangdong Province, China. [J]. BMJ open. 2016;6:e011388.

5. Deng S, Yang N, Li S, et al. Doctors' job satisfaction and its relationships with doctor-patient relationship and work-family conflict in China: a structural equation modelling [J]. Inquiry 2018;55(1):004695801879083.

6. Fan $\mathrm{H}$, Yin W, Guo $\mathrm{H}$, et al. Analysis on the influencing factors of rural doctors' work enthusiasm under the policy of "Ten Thousand Health Care Doctors Entering Rural Households" [J]. Chinese Journal of Hospital Administration. 2014;30(5):347-50. 
7. Haas JS, Cook EF, Puopolo AL, et al. Is the Professional Satisfaction of General Internists Associated with Patient Satisfaction? [J]. J Gen Intern Med. 2000;15(2):122-8.

8. Meng Q, Yuan J, Jing L, et al. Mobility of primary health care workers in China [J]. Hum Resour Health. 2009;7(1):24.

9. Notification of the State Council on Printing and Distributing the Recent Key Implementation Plan for the Reform of Medical and Health System. (2009-2011). http://www.gov.cn/zwgk/200904/07/content_1279256.htm (2020-06).

10. Guiding Opinions of the General Office of the State Council on Promoting the Construction of Graded Diagnosis and. System T. http://www.gov.cn/zhengce/content/2015-09/11/content_10158.htm (2020-06).

11. The Central Committee of the Communist Party of China and the State Council issued the Strategic Plan for Rural Revitalization. (2018-2022). http://www.gov.cn/xinwen/201809/26/content_5325534.htm (2020-06).

12. Li Y, Yang J, Song $\mathrm{H}$, et al. Analysis on the status quo and causes of rural doctors' income structure in Qianjiang of Hubei Province [J]. Med Soc (Berkeley) 2020;(02):6-9.

13. Ma H, Hou J, Zhang J, et al. Moral education training of rural doctors on the job at the stage of academic education [J]. Journal of Jilin Medical College. 2020;41(01):74-5.

14. Zhao R, Liu F. Research on improving the ability of rural doctors under the background of rural Revitalization strategy [J]. Journal of Mudanjiang Medical University. 2019;40(06):160-2.

15. Chen $C$, Yang $X$, Jiang $T$, et al. Investigation on the survival and development of rural Doctors in Sichuan mountainous Areas [J]. Rural Economy Science-Technology. 2019;30(22):192-4.

16. Huang $X$, Yin J, Yao J, et al. Analysis of rural doctors' burden in Shandong Province [J]. Health Vocational Education. 2019;37(22):125-7.

17. Li H, Li X, Xing X, et al. Implementation of contracted medical services and relevant countermeasures in rural areas of Tianshui city, Gansu province: a cross sectional survey among residents and village doctors [J]. Chinese Journal of Public Health, Article in Press Published Online First: 2019-10-23. http://kns.cnki.net/kcms/detail/21.1234.R.20191023.1105.016.html.

18. Chen S, Chen F, Zhang C, et al. Analysis on the Prevalence and Influencing Factors for Job Burnout among Rural Doctors in Taian [J]. Chinese Primary Health Care. 2019;33(10):29-31.

19. Guo J. Research on the relationship among rural doctors' occupational identity, occupational embeddedness and intention willingness-Taking an area of Hennan Province as an example [D]. Guangxi university 2019:20.

20. Zhang Q, Chen J, Yang M, et al. Current status and job satisfaction of village doctors in western China [J]. Medicine. 2019;98(32):e16693.

21. Zhang $X$, Fang P. Job satisfaction of village doctors during the new healthcare reforms in China [J]. Australian health review: a publication of the Australian Hospital Association. 2016;40(2):225. 
22. Ding H, Yang D. A survey on the satisfaction of village doctors in Nanjing and its countermeasures [J]. Management of Health Service in Jiangsu Province. 2020;31(02):246-9.

23. Sun Q, Duan L, Kang $X$, et al. Monthly income satisfaction and its influencing factors of rural doctors in Sanmenxia, Henan province [J]. Guangxi Medical Journal. 2018;40(01):69-72.

24. Chen R, Zhao F, Nie P, et al. Investigation and Analysis of Satisfaction and Demand of Rural Doctors under Student Registration System [J]. Medical Information. 2018;31(23):131-2 + 135.

25. Miao Y, Li L, Bian Y. Gender differences in job quality and job satisfaction among doctors in rural western China [J]. BMC Health Serv Res. 2017;17(1):848.

26. Shen B, Hu L, You L, et al. Turnover Intention and Its Influencing Factors among Village Doctors in Central China [J]. Chinese General Practice. 2018;21(34):4183-7.

27. Liu Y, Kang J. Turnover intention of rural doctors: impact of comprehensive security level, job satisfaction and occupational commitment-empirical evidence from Tibetan and Qiang Minority areas [J]. Rural Economy 2019;(12):130-136.

28. Yin W, Li Y. Scale establishments on job satisfaction and stability of doctors from public hospitals [D]. Weifang Medical University 2007:52-61.

29. Zhang $Y$, Feng $X$. The relationship between job satisfaction, burnout, and turnover intention among physicians from urban state-owned medical institutions in Hubei, China: a cross-sectional study [J]. BMC Health Serv Res. 2011;11(1):235-5.

30. Sun K, Yin W, Huang D, et al. Key influence factors and countermeasures on physicians' satisfaction level [J]. Chinese Health Quality Management. 2009;3:43-6.

31. Yin W, Fu H, Yan F, et al. Evaluation on the Current State of Job Satisfaction and Stability of Community Health Services Staff in Three Cities [J]. Chinese Journal of Health Statistics 2006; (05):421-425.

32. Yin W, Wang K, Fu H. Research on the scope of job satisfaction and stability of community health workers [J]. Chinese Journal of Hospital Administration 2003;(06):35-39.

33. Xu B. Practice and thinking on the construction of family planning team in basic health units [J]. China Health Human Resources 2015;(10):59-61.

34. Li J. Research on the development and countermeasures of village clinics in Hangzhou in the context of New Medical Reform Policy [D]. Hangzhou Normal University 2012:49.

35. Xu Q, Chen Z, Yang Z, et al. Analyzing the Residents Satisfaction on Integration Management of City and Village Health in HaiNan [J]. Med Soc (Berkeley). 2011;24(04):50-3.

36. Qin X, Yin W, Huang D, et al. Changes of occupational psychology of primary healthcare doctors after new health care reform: a comparative study among the questionnaire surveys in 2007, 2011 and 2013 [J]. Chinese General Practice. 2015;18(26):3203-7.

37. Guan H, Yin W, Cui X, et al. Comprehensive Evaluation on Prescription Appropriateness Indicators of Village Doctors in 11 Counties of Shandong Province Before and After the Implementation of National Essential Medicine Policy [J]. Chinese General Practice. 2014;17(31):3758-61. 
38. Yu Q, Yin W, Huang D, et al. Study on the Present Situation of Income Compensation of Rural Doctors under the New Medical Reform and Countermeasures [J]. Chinese General Practice. 2014;17(28):3356-8.

39. Zhou S, Sun J, Duan R, et al. Research on Compensation Policy of a Village Clinic in a County of Inner Mongolia [J]. Chinese Health Economics. 2014;33(12):81-4.

40. National Health Commission of the People's Republic of China, etc. The Opinions on Promoting Progressive Equalization of Basic Public Health Services. Available at: http://www.moh.gov.cn/mohzcfgs/s9660/200907/ 41745.shtml. (Accessed July 14, 2020).

41. Department of Primary Health, National Health Commission of the People's Republic of China. Notice on Doing Well the Work of Basic Public Health Service Projects in 2019. Available at: http://www.nhc.gov.cn/jws/s7881/201909/83012210b4564f26a163408599072379.shtml. (Accessed Mar. 17, 2020).

42. Yin W, Tang C, Feng Z, et al. Analysis on the Supply-side of Rural Clinics from the Perspective of Hierarchical Diagnosis and Treatment [J]. Chinese Health Economics. 2017;36(05):65-8.

43. Chen Z, Yin W, Song J, et al. Analysis on Economic Vulnerability of Village Clinics in Shandong after the New Medical Reform [J]. Chinese Health Economics. 2017;36(06):55-9.

44. Hu X, Pu C, Lin H, et al. Analysis of Performance Assessment Situation of Basic Public Health Services in Chongqing [J]. Chinese General Practice. 2014;17(29):3527-30.

45. Jia H, Yin W, Feng Z, et al. Study on motivational preferences of rural doctors in Shandong province [J]. Chinese Journal of Hospital Administration. 2018;34(3):226-30.

46. Li R. Research on incentive and compensation of rural doctors in the medical reform [D]. Shandong University 2013:38.

47. Therese H, Wu D, Mao LN, et al. Violence against doctors in China [J]. BMJ. 2012;345:e5730.

48. Wu D, Wang Y, Lam KF, et al. Health system reforms, violence against doctors and job satisfaction in the medical profession: a cross-sectional survey in Zhejiang Province, Eastern China. [J]. BMJ open. 2014;4(12):e006431.

49. Gong X, Ruan J. Study on the basic problems of medical liability insurance for rural doctors-based on the results of questionnaire survey [J]. Journal of Chifeng University. 2015;31(05):69-70.

50. Wang G, Lv B, Wang $Y$, et al. Surveying the rural residents' willingness of primary diagnosis in Shandong, Henan and Sichuan province under the background of graded diagnosis and treatment [J]. Chinese Health Service Management. 2018;35(11):842-6 + 869 .

51. Chen Z, Ren G, Yin W, et al. Formation mechanism of the weakening of village clinic' s medical service capacity in Shandong province [J]. Chinese Journal of Hospital Administration. 2020;36(1):32-6.

52. Zhang T, He K. Present Situation and Policy Suggestions of Village Clinics and Rural Doctors in Yidu under the Background of New Medical Reform [J]. Chinese Health Economics. 2016;35(08):22-4. 
53. Chen Z, Yin W, Zheng J, et al. Problems about performance of the essential medicine system based on the Smith-Model [J]. Chinese Journal of Hospital Administration 2015;(31):28.

54. Zhao Y, Yin W, Yu Q, et al. Analysis of influence factors for rational drug use by rural doctors in the essential medicine system [J]. Chinese Journal of Hospital Administration 2015;(31):741.

55. Group WB, Organization WH, Finance PRMO. Deepening Health Reform in China [J]. World Bank Publications 2016:32-33.

56. Gan $Y$, Gong $Y$, Chen $Y$, et al. Turnover intention and related factors among general practitioners in Hubei, China: a cross-sectional study [J]. BMC Fam Pract. 2018;19(1):74. 